\title{
PENERAPAN METODE CERTAINTY FACTOR UNTUK DIAGNOSA PENYAKIT TANAMAN SINGKONG PADA PT. BW TULANG BAWANG
}

\author{
Rengga Adinata ${ }^{1}$, Sita Muharni ${ }^{2}$, M. Adie Syaputra ${ }^{3}$ \\ ${ }^{1}$ Program Studi Teknik Informatika, STMIK Dharma Wacana \\ ${ }^{2}$ Jalan Kenangan No.3 Mulyojati Kota Metro, Lampung \\ Email : rangga.cv@gmail.com
}

\begin{abstract}
ABSTRAK
Singkong atau ubi kayu merupakan pohon tropika dan subtropika. Di indonesia singkong menjadi salah satu olahan pangan karena karbohidratnya dan dapat dijadikan keripik, produksi hasil pertanian singkong merupakan produksi terbesar dan memiliki potensi sebagai bahan baku yang penting. Penghasil singkong terbesar sendiri berada di lampung, akan tetapi kualitas singkong dinegara kita sangat menurun. Salah satu hal penyebab yang membuat kualitas singkong adalah penyakit yang menyerang tanaman ubi kayu atau singkong, dengan adanya permasalahan tersebut agar dapat membantu petani dalam menangani masalah maka perlu dibangun sebuah sistem dalam mendiagnosa penyakit tanaman singkong dengan menggunakan metode certainty factor. Sistem menggunakan metode certainty factor ini memilih gejala yang dialami pada tanaman singkong kemudian menggunakan nilai interprestasi, maka sistem akan menghasilkan diagnosa penyakit tersebut. Hasil uji coba aplikasi ini sistem mampu mengidentifikasi jenis penyakit.
\end{abstract}

Kata Kunci: Certainty Factor, Sistem Pakar, Singkong, Website

\section{PENDAHULUAN}

\subsection{Latar Belakang Masalah}

Tanaman singkong merupakan tanaman yang menjadi salah satu komoditas pertanian di Indonesia. Mempunyai lahan yang cukup luas, Indonesia juga memiliki iklim dan tanah tropis, cocok untuk mengembangkan komoditas singkong. Tanaman ini mampu tumbuh di dataran tinggi dan rendah tidak mengenal musim. Provinsi Lampung sendiri merupakan daerah penghasil singkong terbesar di Indonesia. Penghasil singkong di Provinsi Lampung adalah Kabupaten Tulang Bawang dengan luas panen singkong mencapai 19,886/Ha dan produksi singkong yang dihasilkan mencapai 494,615 ton. Kabupaten Tulang Bawang merupakan salah satu penyangga pangan terutama untuk komoditi singkong yaitu sebesar 248,73 Kuintal per Ha. (Badan Pusat Statistik,2017).

Kerusakan pada tanaman singkong ini diakibatkan penyakit dan menjadi salah satu ancaman yang dapat mengurangi produktifitas singkong. Penanggulan yang dilakukan masih secara sederhana, terkadang tidak sesuai yang diharapkan. Hal ini dapat berdampak pada kualitas hasil panen dan tingkat produktifitas dari komoditi singkong tersebut. Keterbatasan informasi menjadi salah satu hambatan petani yang mengakibatkan lambatnya penanganan pada lahan yang terkena penyakit tersebut, hal ini dapat mengakibatkan meluasnya penyakit yang menyerang lahan tersebut kelahan yang lain .Maka diperlukan sebuah sistem yang dapat memudahkan masyarakat terutama petani untuk mengetahui mendiagnosis penyakit ter sebut serta penanggulangan.

Dalam bidang komputer dan informatika, kerumitan dan kesulitan dapat ditanggulangi dengan menyediakn suatu perangkat lunak (sistem pakar) maka digunakan metode certainty factor yang merupakan salah satu teknik untuk mengatasi ketidakpastian dalam mengambil keputusan. Metode certainty factor dipilih karena metode ini cocok dalam proses penentuan identifikasi penyakit, dan hasil dari penerapan metode ini adalah persentase. Persentase sistem disini merupakan tingkat akurasi penentuan penyakit yang menjangkiti tanaman singkong.

Berdasarkan kesimpulan diatas ini menerapkan sistem pakar berbasis web yang dapat mengiagnosa penyakit menyerang tana man singkong di kabupaten Tulang bawang. 


\subsection{Metode Certainty Factor (CF)}

Metode certainty factor merupakan faktor kepastian. Suatu metode yang digunakan untuk menyatakan kepastian dalam sebuah insident (hipotesis atau fakta) yang berdasarkan penilaian pakar atau bukti yang ada. Untuk dapat mengidentifikasi jenis penyakit maka dapat melakukan perhitungan certainty factor untuk mengetahui nilai $\mathrm{CF}$ dari setiap gejala yang mengidetifikasi jenis hipotesis. Hasil dari peritungan ini akan digunakan dalam proses perhitungan combine CF berdasarkan evidance. Kesimpulan dalam mengidentifikasi penyakit tanaman singkong dapat didapatkan dari hasil perhitungan combine $\mathrm{CF}$ berdasarkan gejala yang terjadi. Dalam mengungkapkan tingkat keyakinan digunakan suatu nilai CF untuk mengasumsikan tingkat keyakinan oleh seorang pakar dalam menentukan suatu data. Berikut adalah Rumus dasar dari Certainty Factor sebagai berikut :

a. Rumus 1 hipotesa mempunyai $1 \mathrm{CF}$ rule, 1 evidence, dan $1 \mathrm{CF}$ evidence.

\section{Dimana:}

$$
\mathbf{C F}[\mathbf{H}, \mathbf{E}]=\mathbf{C F}[\mathbf{E}] * \mathbf{C F}[\text { Rule }]
$$

1. $\mathrm{CF}[\mathrm{H}, \mathrm{E}]$ : cf dari hipotesis yang dipengaruhi evidence

2. $\mathrm{CF}[\mathrm{E}]=$ besar $\mathrm{CF}$ dari evidence

3. $\mathrm{CF}[$ Rule $]=$ besar $\mathrm{CF}$ dari pakar

b. Rumus 1 hipotesa mempunyai $1 \mathrm{CF}$ rule, banyak evidence, dan banyak CF evidence

\section{$\mathrm{CF}[\mathrm{H}, \mathrm{E}]=\min \{\mathrm{CF}[\mathrm{E} 1]|\mathrm{CF}[\mathrm{E} 1]| \mathrm{CF}[\mathrm{En}]\}$ * CF[Rule]}

Dimana:

1. $\mathrm{CF}[\mathrm{H}, \mathrm{E}]$ : cf dari hipotesis yang dipengaruhi evidence

2. $\mathrm{CF}[\mathrm{E}]=$ besar $\mathrm{CF}$ dari evidence

3. $\mathrm{CF}[\mathrm{Rule}]=$ besar $\mathrm{CF}$ dari pakar

c. Rumus banyak hipotesa mempunyai banyak evidence, dan banyak CF evidence.

Jika kedua $\mathrm{CF}>0$, maka rumusnya adalah:

$\mathrm{CF}[\mathrm{H}, \mathrm{E}]=\mathrm{CF}$ [lama] + CF[baru] (1-CF[lama])

Jika kedua $\mathrm{CF}<0$, maka rumusnya adalah:

$\mathrm{CF}[\mathrm{H}, \mathrm{E}]=\mathrm{CF}[\mathrm{lama}]+\mathrm{CF}[\mathrm{baru}](\mathbf{1}+\mathrm{CF}[\mathrm{lama}])$

Jika kedua salah satu $\mathrm{CF}<0$, maka rumusnya adalah:

Dimana:

\section{$\mathrm{CF}[\mathrm{H}, \mathrm{E}]=\mathrm{CF}[\mathrm{lama}]+\mathrm{CF}[\mathrm{baru}] / \mathrm{1}$ - $\min (\mathrm{CF}$ [lama] | CF[lama])}

1. $\mathrm{CF}[\mathrm{H}, \mathrm{E}]$ : cf dari hipotesis yang dipengaruhi evidence

2. $\mathrm{CF}[$ lama $]=\mathrm{CF}$ pertama atau $\mathrm{CF}$ hasil perhitungan sebelumnya

3. $\mathrm{CF}[$ baru $]=\mathrm{CF}$ kedua atau $\mathrm{CF}$ selanjutnya
Metode certainty factor mempunyai kelebihan dan kekurangan, adapun kelebihan dari metode certainty factor antara lain :

1. Metode ini cocok dipakai dalam sistem pakar untuk mengukur sesuatu apakah pasti atau tidak pasti dalam mendiagnosis dan mengidentifikasi.

2. Perhitungan dengan metode ini dalam sekali hitung hanya dapat mengolah dua data saja sehingga keakuratan data dapat terjaga.

Adapun kekurangan dari metode certainty factor antara lain:

1. Ide umum dari pemodelan kepastian manusia dengan menggunakan numeric certainty factor biasanya diperdebatkan sebagian orang akan membantah pendapat bahwa formula untuk metode certainty factor diatas memiliki sedikit kebenaran.

2. Metode ini dapat mengolah ketidakpastian / kepastian hanya dua data saja perlu dilakukan beberapa kali pengolahan data untuk data yang lebih dari dua buah

\subsection{HASIL DAN PEMBAHASAN}

A. Basis Pengetahuan

Gejala penyakit tanaman singkong yang membuat hasil panen petani menurun ditunjukan pada tabel 1. Jenis penyakit tanaman singkong dintara lain yaitu hawar bakteri, layu bakteri, bercak coklat, daun baur, Daun Phyllostica, jenis dan kode penyakit ditunjukan pada tabel 2.

Tabel 1. Gejala Penyakit

\begin{tabular}{|c|l|c|}
\hline Kode & \multicolumn{1}{|c|}{ Gejala } & Bobot \\
\hline G01 & Bercak Berwarna Coklat & 0,4 \\
\hline G02 & Bercak Bentuk Tidak Teratur & 0,8 \\
\hline G03 & Daun Gugur Dan Mati Ujung & 0,2 \\
\hline G04 & Tanaman Layu & 0,6 \\
\hline G05 & $\begin{array}{l}\text { Tiap Bercak Meliputi Seperlima } \\
\text { Dari Luas Helaian Daun }\end{array}$ & 1,0 \\
\hline G06 & $\begin{array}{l}\text { Bercak Daun Tanpa Batas Yang } \\
\text { Jelas }\end{array}$ & 1,0 \\
\hline G07 & Daun Berwarna Coklat & 0,8 \\
\hline G08 & $\begin{array}{l}\text { Bercak Dengan Tepi Yang } \\
\text { Kurang Jelas }\end{array}$ & 1,0 \\
\hline G09 & $\begin{array}{l}\text { Bercak Besar Dan Berwarna } \\
\text { Coklat }\end{array}$ & 0,6 \\
\hline G10 & Bercak Bercak Besar Pada Daun & 0,2 \\
\hline G11 & $\begin{array}{l}\text { Bercak Bersudut-Sudut } \\
\text { (Angular) }\end{array}$ & 1,0 \\
\hline G12 & Bercak Kebasah Basahan & 0,2 \\
\hline G13 & Bercak Daun Besar & 1,0 \\
\hline
\end{tabular}


Tabel 2. Jenis Penyakit

\begin{tabular}{|c|l|}
\hline Kode & \multicolumn{1}{|c|}{ Nama Penyakit } \\
\hline P01 & Hawar Bakteri \\
\hline P02 & Layu Bakteri \\
\hline P03 & Bercak Coklat \\
\hline P04 & Daun Baur \\
\hline P05 & Daun Phyllostica \\
\hline
\end{tabular}

\section{B. Rule CF}

Penerapan metode certainty factor diperlukan beberapa rule dengan memberikan nilai bobot gejala oleh seorang pakar. Pakar memberikan nilai bobot untuk setiap gejala dari 0,2-1,0 dapat ditunjukan pada tabel 3 .

Tabel 3. Nilai Interprestasi CF

\begin{tabular}{|c|l|c|}
\hline No & \multicolumn{1}{|c|}{ Keterangan } & Bobot \\
\hline 1 & Ragu-ragu & 0,2 \\
\hline 2 & Mungkin & 0,4 \\
\hline 3 & Sangat Mungkin & 0,6 \\
\hline 4 & Hampir Pasti & 0,8 \\
\hline 5 & Pasti & 1,0 \\
\hline
\end{tabular}

\section{Perhitungan Metode Certainty Factor pada} Suatu Kasus

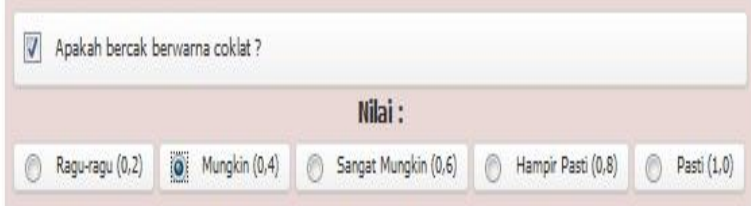

1. Menentukan nilai Certainty Factor pakar untuk masing-masing premis (ciri).

\begin{tabular}{|c|c|c|}
\hline Kode & Nama Gejala & $\begin{array}{c}\text { CF } \\
\text { Rule }\end{array}$ \\
\hline GO1 & Apakah Bercak Berwarna Coklat & 0,4 \\
\hline
\end{tabular}

2. Penentuan Certainty Factor User

\begin{tabular}{|c|l|l|c|}
\hline Kode & \multicolumn{1}{|c|}{ Nama Gejala } & Jawaban & $\begin{array}{c}\text { CF } \\
\text { Rule }\end{array}$ \\
\hline G01 & $\begin{array}{l}\text { Daun Bercak } \\
\text { Berwarna Coklat }\end{array}$ & Mungkin & 0,4 \\
\hline
\end{tabular}

3. Rule-rule yang baru tersebut kemudian dihitung nilai Certainty Factor pakar dengan Certainty factor User menggunakan persamaan.

Rumus dasar : $\mathrm{CF}(\mathrm{H}, \mathrm{E})=\mathrm{CF}[\mathrm{E}] * \mathrm{CF}[$ rule $]$

\begin{tabular}{|c|c|}
\hline CF & CF User \\
\hline 1 & 0,4 \\
\hline
\end{tabular}

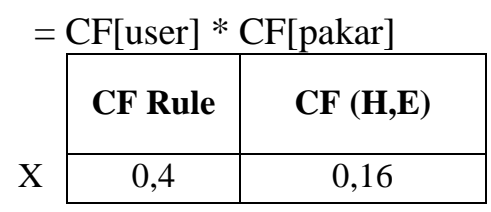

Kesimpulan: $\mathrm{CF}$ terakhir merupakan CFpenyakit, berdasarkan hasil perhitungan $\mathrm{CF}$ di atas, maka $\mathrm{CF}$ penyakit adalah 0,16. Selanjutnya hitung persentase keyakinan terhadap penyakit dengan persamaan.

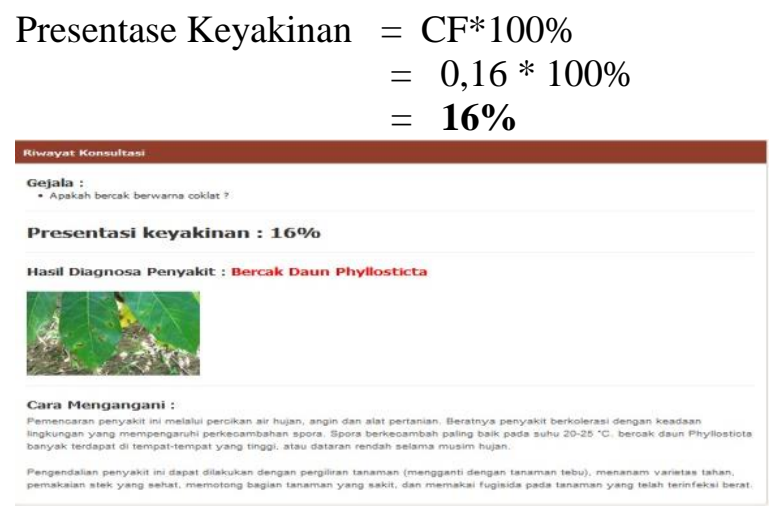

Dengan demikian dapat dikatakan bahwa perhitungan certainty factor yang dilakukan jenis penyakit Bercak Daun Phyllosticta memili ki tingkat keyakinan sistem $16 \%$.

\subsection{Kesimpulan Dan Saran}

\section{A. Kesimpulan}

Berdasarkan penelitian dan hasil pengujian aplikasi maka dapat disimpulkan sebagai berikut :

1. Penerapan metode certainty factor sangat sesuai digunakan pada sistem pakar identifikasi penyakit tanaman singkong sehingga dapat diketahui hasil tingkat kepastian identifikasi penyakit dengan menentukan nilai CF dari beberapa gejala penyakit tanaman singkong dan penentuan CF user kemudian dapat mengidentifikasi penyakit tanaman singkong dengan melihat tingkat akurasi keyakinan dan cara penanganan serta solusinya.

2. Aplikasi sistem pakar untuk mengidentifik asi penyakit pada tanaman singkong dengan menggunakan metode certainty factor dan pemograman PHP dapat membantu meminimalisasi serangan penyakit pada tanaman singkong serta meminimalisasi kerugian yang diderita petani singkong.

\section{B. Saran}

3. Pengembangan disarankan dapat dilakukan dengan menggunakan metode lainnya dan dapat diimplementasikan berbasis web dan android agar sistem pakar dapat digunakan untuk umum. 


\section{DAFTAR PUSTAKA}

Adi Sucipto1, Y. F. (2019). Penerapan Metode Certainty Factor Pada Diagnosa Penyakit Saraf Tulang Belakang. Bandar lampung: Fakultas Teknik dan Ilmu Komputer (FTIK).

Aryasa, K. (2018). Sistem Pakar Diagnosa Penyakit Tanaman Agribisnis Menggunakan Metode Certainty Factor. Indonesia: Sistem Informasi Dan Teknologi Vol.7.

Candra, A. (2017). Sistem Pakar Penyelesaian Metode Certainty Factor. Indonesia.

Durkin, J. (1994). Pengertian Tentang Sistem Pakar dalam program komputer yang dirancang untuk memodelkan kemampuan penyelesaian masalah.

Ginanjar. (2014). rangkaian atau sejumlah halaman web di internet yang memiliki topik saling berkaitan untuk mempresentasikan suatu informasi .

Hidayat, M. (2012). Buku Perancangan Sistem Pakar Menurut Para ahli dalam beberapa definisi Sistem Pakar.

Ignizo. (1991). Sistem pakar adalah suatu model dan prosedur yang berkaitan, dalam suatu domain tertentu, yang mana tingkat keahliannya.

Kadir. (2014). Sistem pengakses informasi dalam internet.

Mohammad Arifin, S. E. (2017). Penerapan Metode Certainty Factor Untuk Sistem Pakar Diagnosa Hama Dan Penyakit Tembakau. Indonesia: Berkala Sainteck.

Panduan, B. (2017). Penulisan Laporan Skripsi. Metro: STMIK Dharma Wacana.

Riley, G. d. (2005). suatu sistem komputer yang bisa menyamai atau meniru kemampuan seorang pakar.

Rudi Haryanto, K. S. (2018). Sistem Pakar Diagnosa Penyakit dan Hama Pada Tanaman Tebu Menggunakan Metode certainty factor. Indonesia: Jointects.

Suharto. (2012). web berbeda, internet menggunakan TCP/IP sebagai protocol sedangkan web menggunakan HTTP (Hyper Text Transfer Protocol).
Sutojo, d. (2011). Landasan Teori Sistem pakar. Jogyakarta.

Sutojo, d. (2013). Perancangan Sistem Pakar Untuk Mengidentifikasi Penyakit Pada Tanaman Semangka Dengan Menggunakan Metode Certainty Factor. Medan: STMIK Budi Dharma. 